\title{
An experimental study on mechanical properties of GFRP braid-pultruded composite rods
}

\author{
M. S. Ahmadi 1 , M. S. Johari ${ }^{*}$, M. Sadighi², M. Esfandeh ${ }^{3}$ \\ ${ }^{1}$ Textile Engineering Department, Amirkabir University of Technology, Tehran, Iran \\ ${ }^{2}$ Mechanical Engineering Department, Amirkabir University of Technology, Tehran, Iran \\ ${ }^{3}$ Composites Group, Iran Polymer \& Petrochemical Institute, Tehran, Iran
}

Received 19 April 2009; accepted in revised form 15 June 2009

\begin{abstract}
In this work, a conventional textile braiding machine was modified and added to a pultrusion line in order to produce glass fiber reinforced composite rods by braiding-pultrusion technique. Braid-pultruded (BP) rods were produced with three braid roving linear densities and also with three different braid angles. To study the influence of overbraiding on mechanical properties of pultruded rods, unidirectional (UD) rods, without braided fabric, were produced, as well. All rod types were subjected to tensile, bending and torsion tests. The experimental results showed that BP rods have considerably higher shear modulus, but lower tensile modulus and flexural rigidity than those of UD pultruded rods, when fiber volume fraction is kept constant. Moreover, rods produced with higher braid roving linear densities had better torsional, but lower tensile and flexural properties. The highest shear modulus was observed in BP rods with braid angle of $45^{\circ}$.
\end{abstract}

Keywords: polymer composites, mechanical properties, braiding, pultrusion, rod

\section{Introduction}

Braiding has traditionally been used for producing textile structures such as shoelaces and ropes. However, in recent years, fiber reinforced composites and medical implants have become interesting application areas for braiding. As a technique for manufacturing preforms for composite structures, braiding has been attracting a great deal of attention. Composite structures reinforced with braided fabrics have a number of advantages over other competing structures such as woven and filament wound composites, as follows. Braided composites have superior toughness and fatigue strength in comparison to filament wound composites. In filament wound composites, cracks propagate readily along the fibers while points of interlacement in braided composites act as crack arresters [1, 2]. Woven fabrics have orthogonal interlacement while the braids can be constructed over a wide range of angles, from 10 to $85^{\circ}$. An additional set of axial yarns can be introduced to the braiding process to produce triaxial braids; triaxial braids are more stable and exhibit nearly isotropic properties [1, 3, 4]. Braids can be produced either as seamless tubes or flat fabrics with a continuous selvedge. Composites produced with the braided fabrics exhibit superior strength and crack resistance in comparison to broadcloth composites, due to fiber continuity [1].

Braided composites have good shear and torsional strength and stiffness. They also offer increased transverse moduli, transverse strength, damage tolerance, dimensional stability and near net shape manufacturing capabilities [5-9].

Braiding can also be integrated with the pultrusion process, which is a well-known method for manu- 


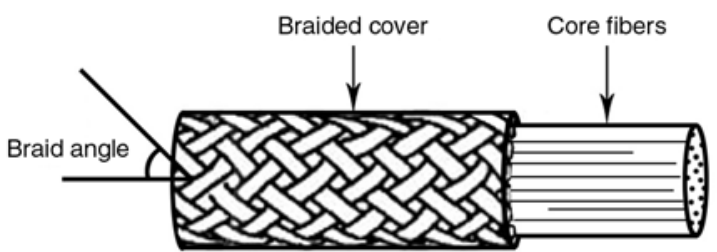

Figure 1. Structure of a BP rod

facturing composite parts in a continuous way. A number of researchers worked on various aspects of braiding-pultrusion process and recommended it as a new low-cost and efficient fabrication technique [10-16].

A simple product of the braiding-pultrusion technique is a braid-pultruded (BP) cylindrical rod which is comprised of a braided cover and a core of unidirectional fibers (Figure 1). Some of the applications and unique features of this kind of rods were investigated in various works [13, 17-19]. However, there are a few works investigating mechanical properties of BP rods. Saito et al. [20] and Hamada et al. [21] investigated the properties of BP rods under crush test and showed that these rods had superior properties in comparison to the unidirectional rods in terms of energy absorption capabilities. They came to the conclusion that when $\mathrm{BP}$ rods are subjected to compressive loads, the braided layer protects the unidirectional core fibers against axial splitting and consequently makes the structure absorb more energy before failure. Hiermer et al. [22] investigated the torsional failure behaviour of cylindrical carbon/epoxy implant rods, which were structurally similar to BP rods. They manufactured the specimens in a manual multi-stage process, in which, first the cylindrical rods were produced from carbon/epoxy plates by means of cutting and grinding, then over-wound with a layer of braided fabric. They showed that the torsional properties of the rods with braided fabric were much better than those without braided fabric. Nevertheless, as in some applications known for BP rods, such as rebars or medical implants, they can be subjected to different types of loading, like tension, torsion and bending [19,22], a comprehensive study on their mechanical behavior under such loading types seems to be of great importance.

Therefore, the aim of this paper is to compare tensile, torsional and flexural properties of GFRP (glass fiber reinforced polymer) braid-pultruded rods to those of their UD counterparts and also to study the effect of some parameters such as braid angle and braid yarn linear density on mechanical properties of BP rods.

\section{Development of a braiding-pultrusion line}

The combination of braiding and pultrusion processes has been also named pull-braiding, braided-pultrusion and braidtrusion in different works. For setting up the braiding-pultrusion production line in the current work, a conventional textile braiding machine was modified at Textile Engineering Department of Amirkabir University of Technology and added to a pultrusion production line at Iran Polymer \& Petrochemical Institute. A schematic of braiding-pultrusion production arrangement used in the present work is shown in Figure 2. Roving strands are unwound from the bobbins held in the creel and pass through an alignment card. The card prevents twisting of the rovings together and at the same time prepares the core part of the braid-pultruded structure which is unidirectional. Once all the fibers are aligned, they are passed through a resin bath. To make sure the fibers

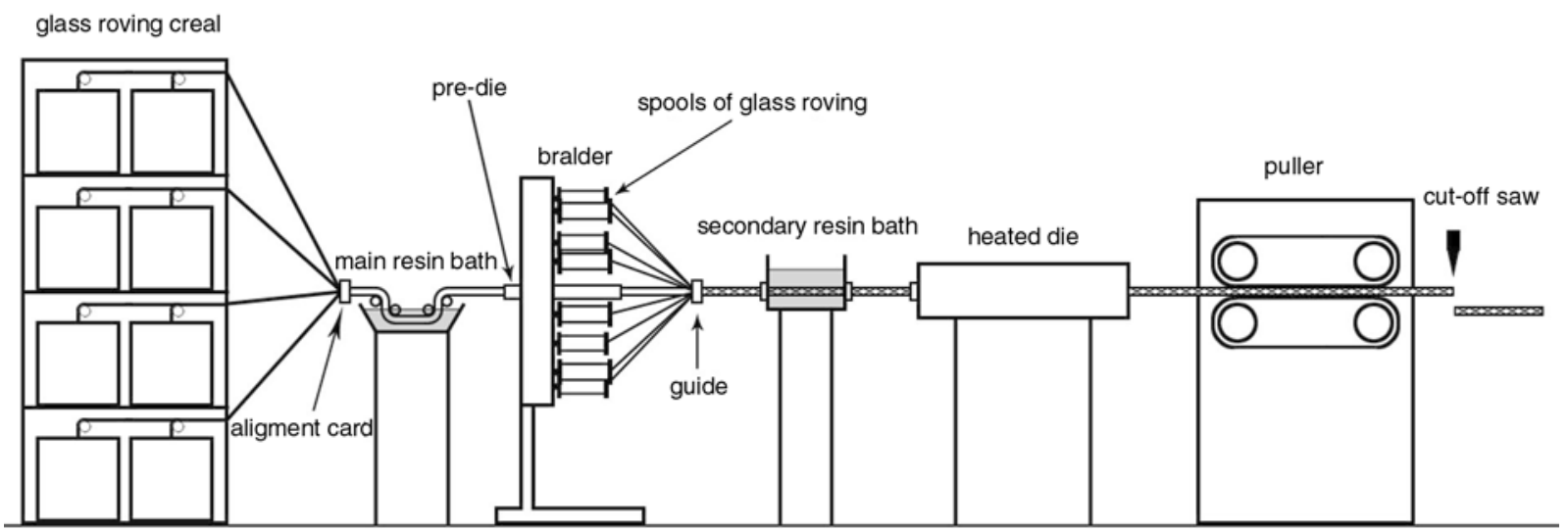

Figure 2. Arrangement of the braiding-pultrusion process used in the present work 
are fully wetted, the strands are passed through a series of rollers, which flatten and spread out the individual roving. The resin used is normally of good and rapid impregnation properties with long gel-time and short curing time. Following the resin bath, the unidirectional fibers are over-braided using the braiding machine.

To be combined with the pultrusion line, in this work, a traditional textile braider was changed from vertical to horizontal configuration and equipped with specially designed spools suitable for winding glass roving. Braid angle, which is the angle between braid yarns and axis of the braid structure and is one of the most important structural parameters affecting mechanical properties of braids (Figure 1), is calculated from Equation (1) [1]:

$\alpha=\tan ^{-1}\left(\frac{\omega \cdot R}{v}\right)$

where $\alpha$ denotes braid angle, $\omega$ average angular velocity of spools around the braider center point, $R$ the core material radius and $v$ take-up speed of the braid.

Changing the braid angle in braiding machines is usually performed by changing the take-up speed. However, in the combination of braiding and pultrusion processes, as all production stages, i.e. resin impregnating, braiding and curing are carried out continuously, any change in take-up rate leads to change in curing time. Hence, in the present work, to change the braid angle, angular velocity of spools around the center of the braider was changed. For this purpose, the braider was equipped with a frequency controlled motor for the spools drive. As a result, all rod types could be produced with the same curing speed, and it was also possible to easily change the braid angle during the process. Moreover, a pre-die was embedded in the center of the braider. The pre-die bundles the unidirectional core fibers together and gives them a circular cross section before being dressed by the braided cover. Wetting the braid yarns with resin can be done in several ways. Using a resin curtain and injecting resin by a resin pump are among them which can be found in various works $[13,15,19,20,23]$. In this work, a secondary resin bath was designed and installed after the braider in order to ensure a perfect wetting of braid yarns, though the excess resin of core fibers in some types with relatively low cover/core fiber weight ratio was almost enough to wet out the braid fibers as they wrapped around them under tension.

After the secondary resin bath, the structure is guided into the heated die at one end and exiting at the other as a cured structural component. The die was $500 \mathrm{~mm}$ in length, $6 \mathrm{~mm}$ in diameter, and with curing temperature of $120^{\circ} \mathrm{C}$. The pulling station is located at the end of the braiding-pultrusion line. A set of padded clamps grip the cross-section and horizontally pull the rod. For the current work, pultrusion was carried out with the speed of $100 \mathrm{~mm} / \mathrm{min}$. The final process in the braided pultrusion technique is the cut-off that is done by the cut-off saw located immediately after the pulling station.

\section{Material and manufacture of rods}

The glass fiber roving used for manufacturing the rods was supplied by CPIC Inc. with the designation ER-469L. The matrix material was unsaturated isophthalic polyester resin with the designation 751129 by Bushehr Chemical Industries Co. Benzoyl peroxide (BPO) supplied by Merck Chemical Co. was used as curing initiator at 3 phr. Release agent of PAT-654/M by CRC Co. was also used in resin formulation at $1 \mathrm{phr}$. Fiber and resin properties are listed in Table 1.

In this study, rods with diameter of $6 \pm 0.1 \mathrm{~mm}$ were produced by braiding-pultrusion method. For all rod types, braiding process was carried out using 8 spools of glass roving and with the diamond pattern ( $1 / 1$ repeat).

For investigating the effect of braid roving linear density, three types of rods were produced using three linear densities of roving; 300, 600 and 900 tex as braided cover roving. The braid angle was kept $45^{\circ}$ in these types. To study the influence of braid angle on the mechanical properties, rods with two other braid angles, i.e. 30 and $55^{\circ}$ were also produced. Moreover, unidirectional rods were pultruded without using braid fibers to investigate the effect of overbraiding.

Table 1. Fiber and resin properties

\begin{tabular}{|l|c|c|c|}
\hline Material specification & $\begin{array}{c}\text { Tensile } \\
\text { strength } \\
{[\mathbf{M P a}]}\end{array}$ & $\begin{array}{c}\text { Tensile } \\
\text { modulus } \\
{[\mathbf{G P a}]}\end{array}$ & $\begin{array}{c}\text { Density } \\
{\left[\mathbf{g} / \mathbf{c m}^{\mathbf{3}}\right]}\end{array}$ \\
\hline Glass fiber, ER-469L & 1700 & 73 & 2.5 \\
\hline $\begin{array}{l}\text { Unsaturated Isophthalic } \\
\text { Polyester resin, 751129 }\end{array}$ & 55 & 4 & 1.1 \\
\hline
\end{tabular}


Table 2. Specifications of manufactured rods

\begin{tabular}{|c|c|c|c|c|c|}
\hline Rod type & $\begin{array}{c}\text { Linear density of } \\
\text { braid roving [tex] }\end{array}$ & $\begin{array}{c}\text { Linear density of core } \\
\text { fibers [tex] }\end{array}$ & $\begin{array}{c}\text { Braid angle } \\
{\left[{ }^{\circ}\right]}\end{array}$ & $\begin{array}{c}\text { Fiber volume } \\
\text { fraction [\%] }\end{array}$ & $\begin{array}{c}\text { Cover/core fiber } \\
\text { weight ratio [\%] }\end{array}$ \\
\hline $300-45$ & $(300 \times 8)$ & $(2400 \times 18)+1500$ & 45 & 63.1 & 7.7 \\
\hline $600-45$ & $(600 \times 8)$ & $(2400 \times 17)+300$ & 45 & 63.5 & 13.7 \\
\hline $900-45$ & $(900 \times 8)$ & $(2400 \times 15)+1800$ & 45 & 63.4 & 26.9 \\
\hline $900-30$ & $(900 \times 8)$ & $(2400 \times 16)+1200$ & 30 & 63.1 & 21.5 \\
\hline $900-55$ & $(900 \times 8)$ & $(2400 \times 14)$ & 55 & 61.4 & 40.8 \\
\hline UD & - & $(2400 \times 20)$ & - & 60.6 & 0.0 \\
\hline
\end{tabular}

All rods were produced with almost the same fiber volume fraction. Therefore, it was necessary to use the same amount of fibers in the unit length of each rod. Since the amount of fibers in the braided cover changes when braid angle and/or braid yarn linear density change, the total weight of fibers in the unit length of each rod was kept the same by changing the amount of core fibers. After manufacturing the rods, some specimens were prepared for burn-off test in order to measure the actual value of fiber volume fraction. Burn-off test was conducted at $600^{\circ} \mathrm{C}$ for 90 minutes. Cover/core fiber weight ratio was also measured on the specimens after burn-off test by separating braided cover from core and weighing them. The specifications of manufactured rods are listed in Table 2.

The produced rods had good surface quality and accurate dimensions. The results of torsion and bending tests showed there was a good bond between braided cover and unidirectional core. Figure 3 shows some of the manufactured rods (a), and a specimen after burn-off test (b).
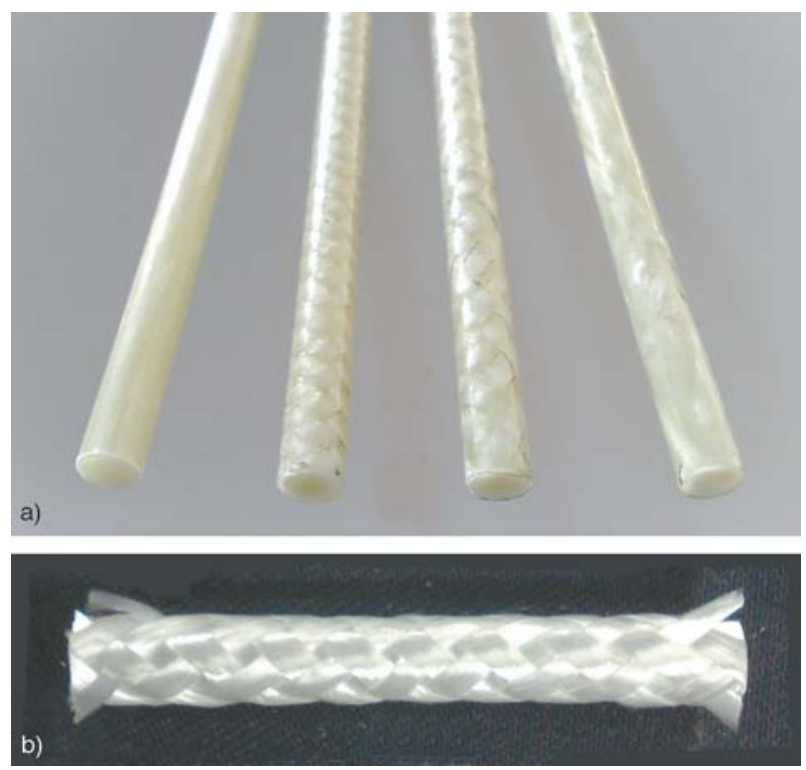

Figure 3. (a) Some manufactured rods and (b) a specimen after burn-off test

\section{Test equipment and procedure}

\subsection{Torsion test}

For preparation of torsion test specimens, rods were cut into pieces of $120 \mathrm{~mm}$ length. All pieces were embedded at the two ends in specially designed steel pipes with epoxy resin. Inner diameter of steel pipes was designed to be $6.2 \mathrm{~mm}$ in order to make sure the rods are aligned in the center of both pipes. To ensure that the rods will not twist in the pipes under torsional load, one steel pin was used at each end (Figure 4). Four specimens were prepared from each type for torsion test.

The specimens were tested by torsion tester machine STS-50, which was developed by Santam Engineering Design Co. (Figure 5). Twisting the specimens was carried out manually, and the torque associated with each twist angle was shown digitally on the machine. The torque-angle curve was plotted for each rod type using the measured data. In order to analyze shear performance of rods, their shear modulus was calculated (Equations (2) and (3)). For cylindrical rods subjected to torsional loads:

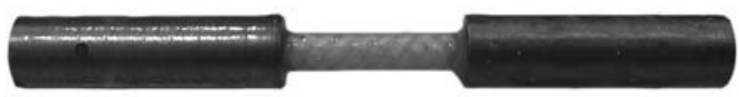

Figure 4. Photograph of a torsion test specimen

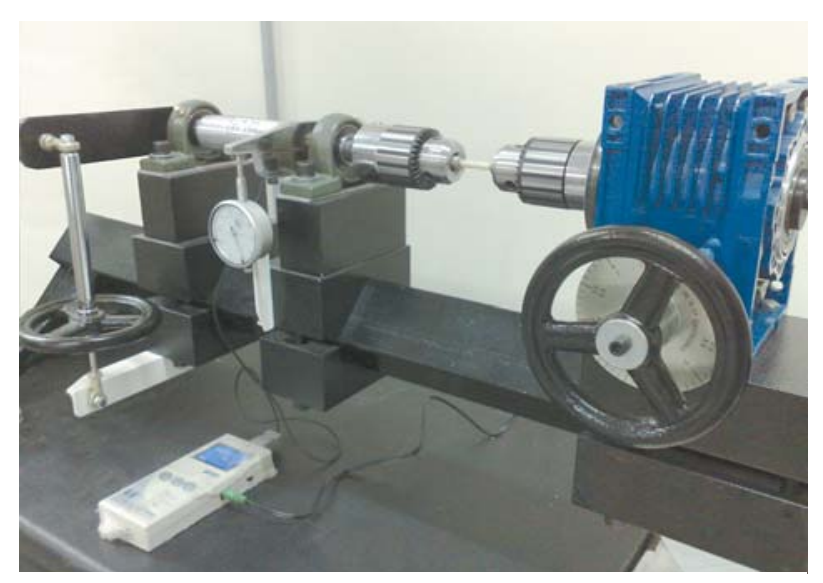

Figure 5. Torsion tester machine 
$G=\frac{T L}{J \theta}$

$J=\frac{\pi D^{4}}{32}$

where $G$ denotes shear modulus of elasticity, $T$ torsional torque, $J$ polar inertia moment for circular cross sectional area, $\theta$ angle of twist, $L$ length and $D$ diameter of the rod.

Based on Equations (2) and (3), shear modulus of elasticity was calculated for each rod type.

\subsection{Tensile test}

For measuring tensile modulus of produced rods, three specimens were prepared from each type for tensile test. Rods were cut into pieces of $450 \mathrm{~mm}$. Two ends of all specimens were threaded using a soft file and then filament wound with glass fiber and epoxy resin. To achieve this, sufficient length of glass roving was impregnated with epoxy resin and wound around $100 \mathrm{~mm}$ length of each end of the specimens, until it reached the diameter of about $15 \mathrm{~mm}$. After curing, the ends were ground and polished in order to reach uniform cylindrical shapes. Three specimens were prepared from each type for tensile test.

The specimens were then tested by the universal testing machine STM-150 made by Santam Engineering Design Co., using an extensometer and with cross head speed of $5 \mathrm{~mm} / \mathrm{min}$. Stress-strain

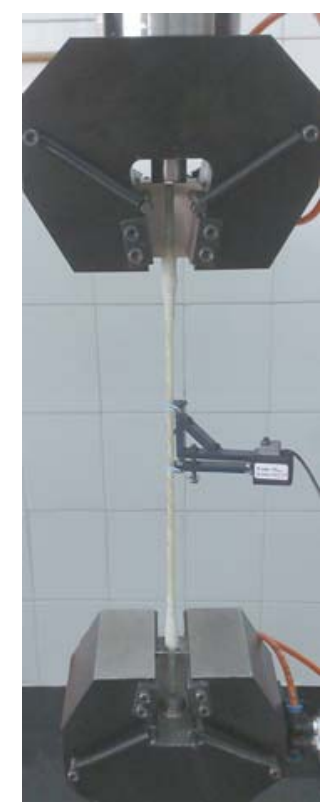

Figure 6. A specimen during tensile test

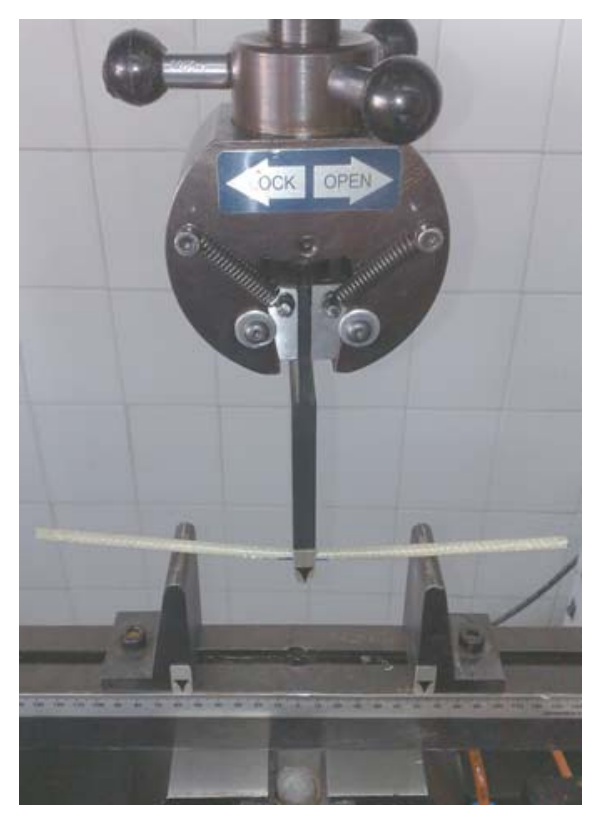

Figure 7. A specimen under bending test

data series were measured and tensile modulus was calculated for each specimen. Figure 6 shows a specimen during tensile test.

\subsection{Bending test}

Three point bending test was also carried out by the universal testing machine STM-150 (Figure 7). The specimens were supported over a span of $120 \mathrm{~mm}$. However, they were made of longer length in order to ensure they do not slip from the supports. Four specimens from each type were tested with loading rate of $5 \mathrm{~mm} / \mathrm{min}$. The bending loads versus deflections were measured until failure and then flexural rigidity values of all specimens were calculated. For components subjected to flexural load, flexural rigidity can be computed using Equation (4):

$$
E I=\frac{P L^{3}}{48 \delta}
$$

where $E I$ is flexural rigidity, in which $E$ and $I$ are modulus of elasticity and the second moment of inertia of the beam section, respectively, $P$ is concentrated load acting on a simply supported beam, $L$ is the beam span length and $\delta$ is deflection.

\section{Results and discussion}

Using the data measured in the torsion test, torqueangle curves for all rod types were plotted (Figures 8 and 9). From these figures some phenomena 


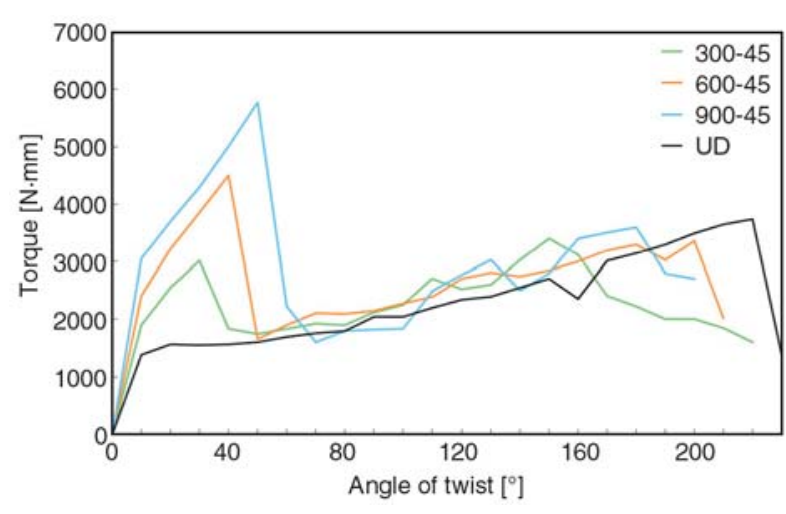

Figure 8. Torque-angle curves of the types 300-45, 60045, 900-45 and UD

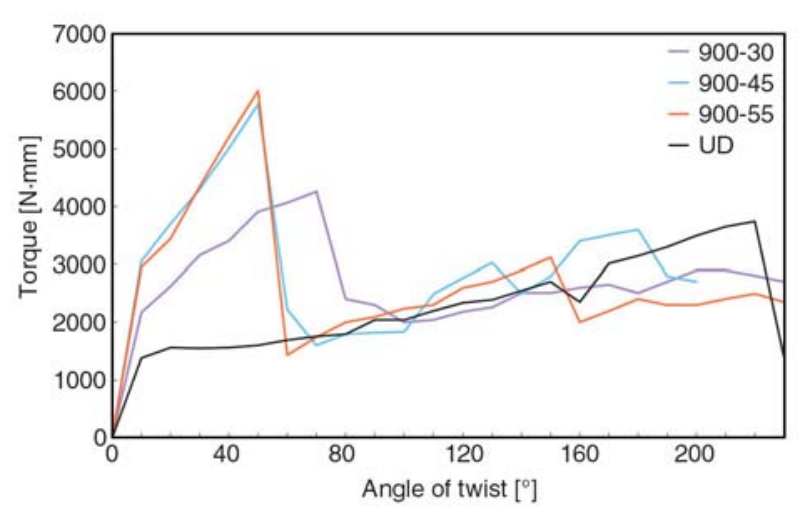

Figure 9. Torque-angle curves of the types 900-30, 90045, 900-55 and UD

can be well identified. Regarding BP rods, it was observed that they had linear torque-angle behavior with no fiber breakage in the beginning of the test. Afterward, fibers in the braided cover started to break gradually. Torque increased with braid angle quasi-linearly, but with a lower slope, in this region until complete failure of braided cover, where torque value collapsed suddenly. At this point the interface between braided cover and UD core was debonded, causing the shear strength to diminish dramatically. This pattern can be seen for all BP rod types.

Considering torque-angle curves of the types 300-45, 600-45 and 900-45 in Figure 8, and also the average calculated shear modulus of the rods which is shown in Figure 10, one can find out that as the braid roving linear density increases, the braid cover fails at higher torques and higher angles. It can also be seen that shear modulus is higher in rods with higher braid roving linear densities.

It may also be noted from the properties of types 900-30, 900-45 and 900-55 that the rods with braid angle of $45^{\circ}$ have the highest shear modulus and

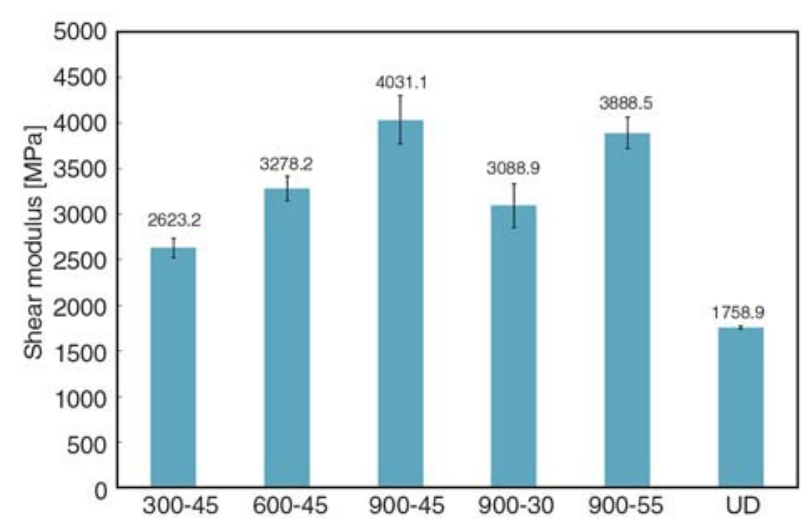

Figure 10. Average shear modulus of the rods

torsional stiffness, which is expected from the theory of composite structures. However, the highest braid cover failure torque was observed in 900-55. It may be because of some manufacturing faults during production or test specimens preparation in the case of 900-45. In fact, the rods with braid angle of $45^{\circ}$ were more subjected to fiber misalignment as the impregnated structure entered the die.

Comparing the torque-angle curve of UD rod to those of braid-pultruded ones (Figures 8 and 9), one can obviously see how overbraiding changes the torsional behavior of rods. The UD rods show an elastic behavior in the beginning and then a combination of such failure mechanisms as matrix cracking and fiber breakage causes the curve to continue with a little increase in applied torque according to the angle. It can be observed that shear modulus of UD rod is the lowest values among those of all $\mathrm{BP}$ ones. It is interesting that in type 300-45, with the lowest braid/core fiber weight ratio, i.e. 0.77 , shear modulus is about 1.5 times higher than that for UD rod.

Although there are a few works investigating the properties of BP rods, comparing the experimental results to those of similar braided structures in the literature shows good agreements [22, 25, 26].

Results from tensile and bending tests showed all rods had linear behavior in tension and flexure. Figures 11 and 12 show average values of elastic modulus and flexural rigidity of the rods, respectively. It is clear that UD rods have the highest elastic modulus and flexural rigidity, which is expected, as they have the highest amount of axially oriented fibers in their structures.

Regarding BP rods, it can be seen that as the braid roving linear density increases, elastic modulus and flexural rigidity fall down. It is due to the fact that 


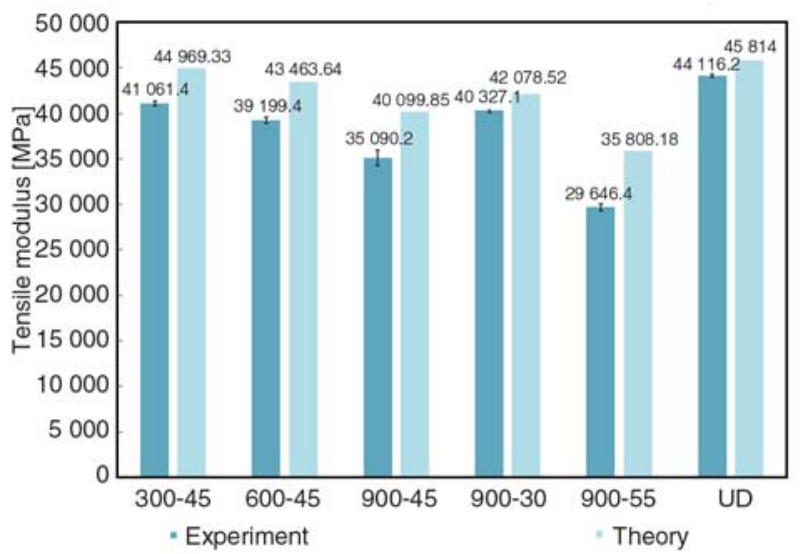

Figure 11. Average experimental tensile modulus of the rods and the theoretical model predictions

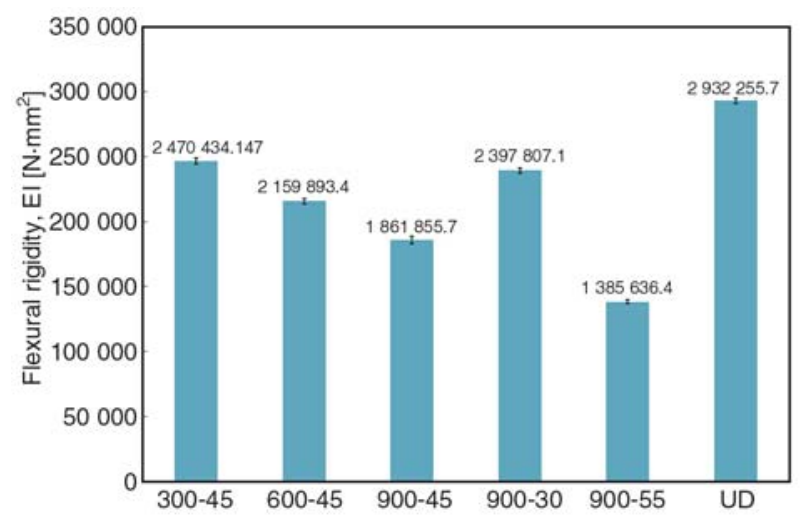

Figure 12. Average flexural rigidity of the rods

all rods were produced with the same fiber volume fraction and therefore, rods with higher braid roving linear density had more amount of radial fibers and less amount of axial core fibers in their structures.

Comparing properties of the types 900-30, 900-45 and 900-55 shows that both elastic modulus and flexural rigidity are higher in samples with lower braid angles, which is due to two reasons. First, decreasing braid angle leads to more contribution of braided cover fibers in resisting axial loads. Second, in samples with lower braid angles, the amount of axial fibers is higher when all rods are to be produced with the same fiber volume fraction.

A simple theoretical model was also utilized to predict the tensile moduli of the rods and compare them to experimental findings. In the model, the structure was assumed to be comprised of two main parts; braided cover and UD core. Tensile moduli were calculated for both parts according to basic formulas of micromechanics, and then were used to calculate the tensile modulus of the whole structure based on the averaging technique [24]. The braided cover was assumed a $[ \pm \theta]$ laminate. Therefore, fiber undulation was neglected in this model. The comparison between experimental tensile moduli and model prediction is shown in Figure 11. Relatively good agreement between the model prediction and the test results can be observed. It can be seen that the model over-predicts the tensile moduli for all types. The main reason for this phenomenon is that fiber undulation is not taken into account in the model.

Moreover, tensile experimental results were in good agreement with those of similar braided structures in the literature $[19,27,28]$. Similar reports on the bending behavior were also observed in some research works [25, 26].

All in all, overbraiding the unidirectional core in pultruded rods, leads to a considerable improvement in their shear modulus and at the same time, a drop in their tensile and flexural properties compared to their UD pultruded counterparts with the same fiber volume fraction and diameter. Comparing the results shows a $56.4 \%$ improvement in shear modulus, a $20.4 \%$ drop in elastic modulus and a $36.5 \%$ drop in flexural rigidity in the type 900-45 compared to UD rod. However, it is a matter of design priorities to find optimum values for braid roving linear density and braid angle in order to achieve desirable torsional properties and at the same time, keep tensile and flexural properties at an acceptable level.

\section{Conclusions}

In this work a braiding-pultrusion production line was developed by modifying a conventional textile braiding machine and adding it to a pultrusion line for production of braid-pultruded (BP) composite rods. With this method it was possible to produce rods with a reinforcement structure comprised of a braided fabric cover and unidirectional core fibers. In order to evaluate mechanical properties of BP rods and study the effect of some braiding parameters, they were produced with different braid roving linear densities and braid angles. The results were also compared to those of unidirectional (UD) pultruded rods which were produced without braided fabric cover, but with the same fiber volume fraction and diameter.

Overbraiding was proved to have a great effect in improving shear performance of pultruded rods. BP 
rods had higher shear modulus compared to UD pultruded rods. Even with the lowest cover/core fiber weight ratio, shear modulus was about 1.5 times higher than that for UD rod. Nevertheless, tensile elastic modulus and flexural rigidity were lower in BP rods compared to UD ones when fiber volume fraction is kept constant.

It was also concluded that increasing the braid roving linear density leads to an improvement in shear modulus, but a reduction in tensile modulus and flexural rigidity.

Moreover, the rod with braid angle of $45^{\circ}$ had higher shear modulus compared to those with braid angles of 30 and $55^{\circ}$. Tensile modulus and flexural rigidity were higher in BP rods with lower braid angles.

\section{References}

[1] Potluri P., Rawal A., Rivaldi M., Porat I.: Geometrical modelling and control of a triaxial braiding machine for producing 3D performs. Composites Part A: Applied Science and Manufacturing, 34, 481-492 (2003).

\section{DOI: $10.1016 / \mathrm{S} 1359-835 \mathrm{X}(03) 00061-7$}

[2] Munro M., Fahim A.: Comparison of helical filament winding and $2 \mathrm{D}$ braiding of fiber reinforced polymeric components. Materials and Manufacturing Processes, 10, 37-46 (1995). DOI: $\underline{10.1080 / 10426919508936925}$

[3] Savino V., Chou T-W.: Mechanical characterization of triaxially braided hybrid composites. Polymer Composites, 19, 473-486 (1998).

DOI: $10.1002 / \mathrm{pc} .10122$

[4] Dadkah M. S., Flintoff J. G., Cox B. N.: Simple models for triaxially braided composites. Composites, 26, 561-577 (1995).

DOI: $10.1016 / 0010-4361(95) 92621-\mathrm{I}$

[5] Byun J. H., Chou T-W.: Modelling and characterization of textile structural composites - A review. Journal of Strain Analysis for Engineering Design, 24, 253-262 (1989).

DOI: $10.1243 / 03093247 \mathrm{~V} 244253$

[6] Hufenbach W., Bla ejewski W., Kroll L., Böhm R., Gude M., Czulak A.: Manufacture and multiaxial test of composite tube specimens with braided glass fiber reinforcement. Journal of Materials Processing Technology, 162-163, 65-70 (2005).

DOI: $10.1016 /$ j.jmatprotec.2005.02.212

[7] Charlebois K. M., Boukhili R., Zebdi O., Trochu F., Gasmi A.: Evaluation of the physical and mechanical properties of braided fabrics and their composites. Journal of Reinforced Plastics and Composites, 24, 1539-1554 (2005).

DOI: $10.1177 / 0731684405050391$
[8] Falzon P. J., Herszberg I.: Mechanical performance of 2-D braided carbon/epoxy composites. Composites Science and Technology, 58, 253-265 (1998). DOI: 10.1016/S0266-3538(97)00133-4

[9] Kessels J. F. A., Akkerman R.: Prediction of the yarn trajectories on complex braided preforms. Composites Part A: Applied Science and Manufacturing, 33, 1073-1081 (2002). DOI: $\underline{10.1016 / \mathrm{S} 1359-835 \mathrm{X}(02) 00075-1}$

[10] Bechtold G., Kameo K., Friedrich K., Hamada H.: Pullbraiding of commingled GF/PP yarn- Influence of processing parameters. in 'The $4^{\text {th }}$ International Symposium for Textile Composites. Kyoto, Japan' O28/1O28/5 (1998).

[11] Fujita A., Nakatani T., Uozumi T., Kameo K., Nakai A., Hamada H.: Crush energy absorption of braided composite rods. in 'The Fifth Japan International SAMPE Symposium. Tokyo, Japan' 1231-1234 (1997).

[12] Hamada H., Ramakrishna S.: Impact performance of glass cloth/epoxy composite tubes with different surface treatment. Composite Interfaces, 4, 35-44 (1996). DOI: $10.1163 / 156855496 \times 00137$

[13] Lam H., Ko F. K.: Composite manufacturing by braidtrusion process. in 'The International SAMPE Technical Conference. Seattle, USA', Vol 33, 532 539 (2001).

[14] Michaeli W., Jürss D.: Thermoplastic pull-braiding: Pultrusion of profiles with braided fibre lay-up and thermoplastic matrix system. Composites Part A: Applied Science and Manufacturing, 27, 3-7 (1996). DOI: 10.1016/1359-835X(95)00004-L

[15] Milwich M., Linti C., Plank H.: Production of fiber reinforced plastic profiles by braid pultrusion. Bandund Flechtindustrie, 38, 42-47 (2001).

[16] Uozomi T., Hisa Y., Fujita A., Hamada H., Nakai A., Yokoyama A.: Braiding pultrusion process (BPP). in 'The International SAMPE Technical Conference, Covina, USA', 27, 371-379 (1995).

[17] Boss J. N., Ganesh V. K.: Fabrication and properties of graded composite rods for biomedical applications. Composite Structures, 73, 289-293 (2006).

DOI: 10.1016/j.compstruct.2005.04.030

[18] Hampton F. P., Lam H., Ko F. K., Harris H. G.: Design methodology of a ductile hybrid FRP for concrete structures by the braidtrusion process. in 'The International SAMPE Symposium and Exhibition. California, USA', Vol 46(II), 2421-2432 (2001).

[19] Harris H. G., Somboonsong W., Ko F. K.: New ductile hybrid FRP reinforcing bar for concrete structures. Journal of Composites for Construction, 2, 28-37 (1998). DOI: 10.1061/(ASCE)1090-0268(1998)2:1(28)

[20] Saito H., Chirwa E. C., Inai R., Hamada H.: Energy absorption of braiding pultrusion process composite rods. Composite Structures, 55, 407-417 (2002). DOI: $\underline{10.1016 / \mathrm{S} 0263-8223(01) 00160-\mathrm{X}}$ 
[21] Hamada H., Kameo K., Sakaguchi M., Saito H., Iwamoto M.: Energy-absorption properties of braided composite rods. Composites Science and Technology, 60, 723-729 (2000).

DOI: $10.1016 / \mathrm{S} 0266-3538(99) 00182-7$

[22] Hiermer T., Schmitt-Thomas Kh. G., Yang Z-G.: Mechanical properties and failure behavior of cylindrical CFRP-implant-rods under torsion load. Composites Part A: Applied Science and Manufacturing, 29, 1453-1461 (1998).

DOI: $\underline{10.1016 / \mathrm{S} 1359-835 X(98) 00027-X}$

[23] Kruesi A. H., Hasko G. H.: Computer controlled resin impregnation for fiber composite braiding. in 'The International SAMPE Symposium and Exhibition. California, USA', Vol 32, 309-317 (1987).

[24] Kregers A. F., Teters G. A.: Use of averaging methods to determine the viscoelastic properties of spacially reinforced composites. Mechanics of Composite Materials, 15, 377-383 (1979). DOI: $\underline{10.1007 / \mathrm{BF} 00605861}$
[25] Potluri P., Manan A.: Mechanics of non-orthogonally interlaced textile composites. Composites Part A: Applied Science and Manufacturing, 38, 1216-1226 (2007).

DOI: 10.1016/j.compositesa.2006.04.008

[26] Potluri P., Manan A., Francke M., Day R. J.: Flexural and torsional behaviour of biaxial and triaxial braided composite structures. Composite Structures, 75, 377 386 (2006).

DOI: $10.1016 /$ j.compstruct.2006.04.046

[27] Huang Z-M.: Efficient approach to the structure-property relationship of woven and braided fabric-reinforced composites up to failure. Journal of Reinforced Plastics and Composites, 24, 1289-1309 (2005). DOI: $10.1177 / 0731684405049860$

[28] Zywicz E., Nguyen T.: On the flexural and extensional behavior of a large-tow triaxial braided composite. Composites Science and Technology, 60, 2989-2999 (2000).

DOI: $\underline{10.1016 / \mathrm{S} 0266-3538(00) 00158-5}$ 